\title{
Histórias de Vida e Saberes Docentes das Educadoras da Zona Urbana e Rural
}

\begin{abstract}
Daniel Bezerra de Brito'
'Universidade do Estado do Rio Grande do Norte (UERN), Natal/RN - Brasil

RESUMO - Histórias de Vida e Saberes Docentes das Educadoras da Zona Urbana e Rural. $\mathrm{O}$ artigo discute o perfil e as narrativas de histórias de vida de 40 educadoras municipais da Educação Infantil da zona urbana e rural do RN. As narrativas revelaram que as trajetórias de vida pessoal e profissional, a partir dos saberes da experiência, têm repercussões nas práticas pedagógicas das educadoras. As relações entre vida pessoal e profissional foram retomadas pela perspectiva sociológica neste artigo como história individual e social entre a educadora e seu grupo de pertença ou campo social. A subjetividade dessas relações contida nas narrativas foi compreendida como informações intencionais, mas que ocultam as retóricas dirigidas pelas educadoras aos grupos de pertença, entre outros, a família, a escola e a profissão.

Palavras-chave: Histórias de Vida. Saberes da Experiência. Formação e Prática Pedagógica.
\end{abstract}

ABSTRACT - Life Accounts and Pedagogic Knowledge from Urban and Rural Teachers. This article discusses the profile and life accounts of 40 local teachers working with preschool education in urban and rural areas within Rio Grande do Norte state. Stories revealed that their personal and professional careers, from experience-based knowledge, affect their pedagogic practices. Links between personal and professional life were assessed in this article from a sociologic perspective, as individual and social histories between educators and the groups or social field to which they belong. The subjectivity of such relations, comprised in the stories, was understood as intentional information, though hiding rhetoric discourses aimed by the educators at their groups - family, school and profession, among others.

Keywords: Life Accounts. Experience-based Knowledge. Pedagogic Training and Practice.

Educação \& Realidade, Porto Alegre, v. 40, n. 3, p. 923-945, jul./set. 2015. 923 http://dx.doi.org/10.1590/2175-623644772 


\section{Introdução}

Desde os anos de 1990, as pesquisas sobre formação docente, incluindo saberes e memoriais autobiográficos ${ }^{1}$, vêm progressivamente ganhando destaque no cenário brasileiro. Segundo Nóvoa (1995), Josso (2004) e Souza (2007), essas pesquisas tentam resgatar a memória dos professores e a unidade das suas dimensões pessoais ${ }^{2}$ e profissionais negligenciadas pelo paradigma da racionalidade técnica que sobreviveu até os anos de 1980 no Brasil. A mudança de paradigma surgiu a partir de um movimento internacional sobre formação docente liderado pelos autores Tardif, Lessard e Lahaye (1991) e Nóvoa (1995), entre outros. Segundo Souza (2007), esse movimento incorporou uma abordagem experiencial que, através de relatos, considera a experiência do sujeito como procedimento de investigação e de formação.

Nessa perspectiva de mudanças de paradigmas, os aportes de Josso (2007) sobre biografias educativas utilizam as histórias de vida ${ }^{3}$ como uma abordagem de pesquisa a serviço de um projeto de investigação e de formação inicial de professores. Os saberes docentes, tais como, os saberes da experiência, curriculares, disciplinares e profissionais aparecem como um dos elementos que norteiam a trajetória da história de vida.

No fervor dessas mudanças, as perspectivas sociológicas de Ferrarotti (1983; 1991); e de Bourdieu (1986; 2001) entraram na educação e passaram a ter importância como objeto de estudo na história de vida de professores. A primeira legitimava as histórias de vida como método autobiográfico de pesquisa e a segunda não as reconhecia como objeto de conhecimento científico.

No ensino da Educação Infantil, o processo de formação docente e a realidade dos profissionais constituem um campo fértil de investigação. O trabalho nesse nível de ensino vive um período de transição entre uma concepção que o definia como de cunho assistencial para outra, que passou a acentuar a dimensão pedagógica de educação e cuidado de crianças bem pequenas (Oliveira et al., 2006). Assim, investigar a educação infantil torna-se um desafio, considerando o seu processo de mudanças atuais e as diferentes concepções e saberes dos professores.

Este artigo considera dois pontos de discussão. O primeiro ponto a ser discutido é a identificação do perfil pessoal e profissional das educadoras investigadas, e visa fornecer dados estatísticos para fundamentar o debate sobre suas histórias de vida. Nessa perspectiva, é pertinente identificar, através de suas narrativas, possíveis diferenças em relação aos níveis de formação, de participação em eventos científicos e do tempo de experiência profissional no interior e na capital do estado do Rio Grande do Norte ${ }^{4}$. O segundo ponto de discussão é a possibilidade de identificar e compreender, através de narrativas, como se articulam as 
dimensões pessoais e profissionais considerando os saberes docentes e as histórias de vida do ponto de vista experiencial e sociológico.

$\mathrm{O}$ artigo pauta pela sua originalidade reconhecendo a inexistência de publicações sobre essa problemática em nível regional. Os objetivos do artigo consideram duas dimensões: 1) discutir sobre o perfil pessoal e profissional de educadoras municipais da Educação Infantil da cidade do Natal e do interior do Rio Grande do Norte; 2) analisar as narrativas autobiográficas sobre história de vida, as articulações entre dimensões pessoais e profissionais ressaltando as perspectivas experienciais e sociológicas, os saberes docentes e as repercussões na prática pedagógica das educadoras.

\section{Breve Perspectiva sobre Formação e Atuação Docente na Zona Rural e Urbana}

Com o advento da Lei Decenal de Diretrizes e Bases da Educação 9.394/1996 educadores da zona rural e urbana, em exercício, apressaram-se em voltar às salas de aulas para realizar cursos de graduação em programas especiais de Pedagogia oferecidos pelas Universidades. Com um nível de formação mais elevado, esse marco contribuiu para a evolução da dimensão pedagógica na educação infantil onde a exigência é menor que no ensino fundamental e médio. A formação mínima exigida legalmente dos profissionais que dão aulas para essas turmas é o diploma de magistério. Ainda assim, 23.363 deles não cumprem essa determinação (13,3\% do total). E apenas 38,2\% desses educadores fizeram curso de graduação (Borges, 2012, p. 1).

No Brasil, durante muito tempo, os investimentos na área da educação têm negligenciado a formação de professores na zona rural, transformando adultos sem a formação mínima, em professores da Educação Infantil. Sem a formação adequada, os professores da zona rural não conseguem cumprir satisfatoriamente seu papel de educadores.

A lei de Diretrizes e Bases da Educação exige o curso de licenciatura plena para quem ensina na Educação Básica. Entretanto, o MEC cita dados do Censo Escolar de 2010 em que 49,9\% dos professores da Educação Básica que ensinam na zona rural não possuem diploma de graduação enquanto que, na zona urbana, a taxa é de apenas $14 \%$. Aproximadamente $75 \%$ dos docentes que atuam na zona rural são mulheres de 36 anos em média e, na zona urbana, elas representam 81,5\% com idade de 39 anos.

O ensino no campo também enfrenta obstáculos como o da infraestrutura das escolas e a ausência de definição de linhas pedagógicas. De acordo com o levantamento do MEC em 2012, 35\% dos professores das 76 mil escolas rurais no Brasil dão aulas sem a formação adequada. Dessa forma, os dados revelam uma significativa desigualdade educacional en- 
tre a cidade e o campo. Urge, portanto, investimentos governamentais na zona rural que eliminem ou amenizem essa desigualdade.

Existe um programa lançado pelo MEC em 2012, o Pronacampo que contempla quatro eixos: 1) Gestão e Práticas Pedagógicas, 2) Formação Inicial e Continuada de Professores, 3) Educação de Jovens e Adultos e Educação Profissional, e 4) Infraestrutura Física e Tecnológica. Considerando que esse programa teve início somente em 2013 ainda não existe uma avaliação definitiva sobre o seu andamento. Entretanto, existe um consenso de que as graduações que forem oferecidas para a formação de professores rurais devam se adequar à realidade do campo sem, portanto, retirá-los do seu meio cultural para estudar nas grandes cidades. Esse consenso refere-se à garantia do acesso ao conhecimento universalmente produzido e a especificidade local, valorizando a vida e a realidade desses educadores. Ao contrário, a saída deles para estudar por um longo período de tempo, poderia gerar o fechamento de escolas em que atuam, tendo em vista que, o Pronacampo não contempla a substituição dos professores participantes do referido programa.

\section{Material e Método}

O estudo se inspirou numa abordagem experiencial de formação e (auto) biográfica (Josso, 2004; 2007); nos saberes da experiência ${ }^{5}$ como elemento norteador da trajetória profissional (Tardif, 1999; Therrien, 1996; Larrosa, 2002) e na subjetividade da dimensão individual e social de duas perspectivas sociológicas divergentes marcadas pelo estudo das histórias de vida (Ferrarotti, 1983; 1991; Bourdieu, 1964; 2001).

Quarenta educadoras ${ }^{6}$ municipais da Educação Infantil das cidades do Natal, de Santa Cruz, Campo Redondo, Japi, Tangará e distritos circunvizinhos participaram deste estudo. Considerando que a maioria do interior é proveniente do campo, seja, zona rural, e que, aquelas da capital são oriundas de áreas urbanizadas as denominarei, respectivamente ao longo deste artigo, de educadoras da zona rural e de educadoras da zona urbana.

O presente artigo faz parte do quadro de um projeto de pesquisa do PIBIC/CNPq na Universidade do Estado do Rio Grande do Norte (UERN) em que sou coordenador de projetos e professor, atuando nas cidades de Natal e de Santa Cruz. O referido projeto começou em 2011 e envolveu graduandos das duas cidades. A minha docência em Santa Cruz com os graduandos provenientes de outras localidades facilitou o encontro com as educadoras das cidades em que eles, os graduandos moravam e elas, as educadoras, viviam e ensinavam. As informações obtidas provêm de cinco escolas da zona urbana e sete da zona rural. Ainda em 2011, os objetivos do referido projeto envolveram três momentos.

No primeiro momento, os graduandos visitaram as escolas para identificar as educadoras interessadas em participar da pesquisa. Em 
seguida, houve um encontro com elas em uma escola nas suas respectivas cidades para explicar os objetivos da pesquisa e a elaboração textual do memorial/questionário. Nesse encontro, com minha presença, ouvimos das educadoras, suas ansiedades, suas rotinas de vida pessoal e profissional as quais solicitamos que fossem acrescentadas nos textos dos memoriais sendo, essa inserção, constatada posteriormente, como uma transcrição de suas próprias oralidades integradas às informações manuscritas. "A narrativa tem a ver com contar histórias. Portanto, ao dizê-las, escutá-las e escrevê-las, aumentam as chances de compartilhar experiências sobre nossas vidas e as vidas de outras pessoas" (Sparkes; Smith, 2003, p. 26). O processo de recolha de informações se repetiu, no mesmo ano, para as escolas municipais na cidade do Natal com o auxílio do bolsista do PIBIC/CNPq. As educadoras responderam o memorial/questionário constituído por duas dimensões visando investigar a trajetória pessoal e profissional delas. A primeira dimensão refere-se às informações do perfil pessoal e profissional as quais foram submetidas à análise quantitativa através de frequência, porcentagem e média aritmética. No perfil pessoal e profissional, as educadoras responderam a cinco categorias para a análise quantitativa: 1) gênero; 2) idade; 3) nível de formação profissional; 4) participação em eventos científicos, e 5) tempo de experiência profissional. Para a análise qualitativa de acordo com as propostas interpretativas de Freitas (2002) e Moita (1994), elas responderam, igualmente, a cinco categorias que se articulam: 1) representação pessoal; 2) vida familiar e escolar; 3) escolha da profissão, 4) formação docente, e 5) atuação docente. Nestas cinco categorias, as educadoras foram orientadas a construir um texto único, mas que, considerassem todas as categorias/questões nos seus manuscritos. Nesse sentido, não as solicitamos destacar detalhes a serem narrados em cada uma das categorias/questões acima, como por exemplo, os conflitos ou as tensões nas suas trajetórias.

No segundo momento foi realizado em 2012 um encontro com as educadoras participantes denominado história de vida e prática docente com o apoio da Secretaria Municipal de Educação de Santa Cruz e teve como objetivos: debater o panorama da formação docente no contexto regional e nacional; discutir a importância da formação continuada e apresentar os primeiros resultados da presente pesquisa.

No terceiro e último momento, os graduandos da UERN das cidades de Santa Cruz e de Natal, apresentaram, sob minha orientação, os resultados da pesquisa em eventos científicos representando separadamente seus respectivos contextos de estudo: rural e urbano.

Finalmente, em 2013, a pesquisa foi redimensionada por mim considerando, simultaneamente, as articulações entre os contextos de estudo rural e urbano em um único artigo científico. 


\section{Análises e Discussões dos Resultados}

Nesta rubrica analiso inicialmente o perfil pessoal e profissional das educadoras da zona rural e urbana. Em seguida, discuto sobre os recortes das narrativas mais significativas das quarenta educadoras considerando suas trajetórias, seus saberes, as articulações das dimensões pessoais e profissionais do ponto de vista experiencial e sociológico e as repercussões na prática docente.

\section{Análise do Perfil Pessoal e Profissional das Professoras da Educação Infantil}

A tabela abaixo mostra as informações pessoais e profissionais considerando sexo, idade, nível de formação, participação em eventos e tempo de profissão das educadoras da zona rural e urbana.

Tabela 1 - Perfil Pessoal e Profissional de Quarenta Educadoras da Zona Rural e Urbana do Estado do Rio Grande do Norte - 2011-2012

\begin{tabular}{|l|c|c|c|}
\hline Informações & Zona Rural & Zona Urbana & Total \\
\hline PROFESSORES (F) & 20 & 20 & 40 \\
\hline SEXO (F) & 02 & & \\
Masculino & 18 & 15 & 07 \\
Feminino & 36 & 38 & 37 \\
\hline IDADE (M) & & & \\
\hline NÍVEL DE FORMAÇÃO & 14 & 04 & 18 \\
PROFISSIONAL (F) & 06 & 16 & 22 \\
Magistério & 04 & 08 & 12 \\
Graduação & & & \\
\hline PARTICIPAÇÃO EM EVENTOS & & & \\
CIENTÍFICOS (F) & & & \\
\hline
\end{tabular}

Fonte: dados organizados pelo autor a partir da coleta de informações da presente pesquisa.

Calculando os resultados das educadoras rurais apresentados na tabela acima, observei que 95\% são mulheres com idade média de 36 anos. Do total de professores, $30 \%$ cursaram a graduação e apenas $20 \%$ participaram de eventos científicos locais. O tempo médio de experiência profissional das educadoras da zona rural é de sete anos e das educadoras da zona urbana é de oito anos.

Em relação aos educadores urbanos, constatei que $75 \%$ deles são mulheres com idade média de 38 anos. Do total de educadores, $80 \%$ cursaram a graduação e $40 \%$ participaram de eventos científicos, tendo a totalidade deles, um tempo de experiência profissional de oito anos.

A presença feminina é menor na zona urbana coincidindo com os indicadores nacionais atuais, segundo os quais, o sexo feminino é 
maioria na educação infantil nas zonas rurais em nível nacional considerando a cultura da mãe-professora mais enraizada na região interiorana. Os resultados regionais aqui obtidos em termos de média de idade de educadores rurais com 36 anos e urbanos com 38 anos, também são semelhantes aos indicadores nacionais, respectivamente 36 e 39 anos (Brasil, 2010). A média relativamente elevada de idade e de experiência profissional da maioria de educadoras rurais e urbanas possibilita uma grande quantidade de informações sobre história de vida e, ao mesmo tempo, contribui para a riqueza de detalhes encontrados nos conteúdos das narrativas. Enfim, possibilita ainda validar na análise qualitativa das referidas narrativas, os conceitos de experiência formativa e dos saberes da experiência propostos por diversos autores (Larrosa, 2002; Josso, 2007; Tardif, 1999).

Os resultados em relação aos itens referentes ao nível de formação e participação em eventos científicos das educadoras urbanas foram mais significativos que aqueles observados com as educadoras rurais. Estes resultados confirmam os indicadores nacionais atuais, segundo os quais, as dificuldades de acesso ao conhecimento ainda são bem maiores para as educadoras da zona rural em relação àquelas da zona urbana. Esses indicadores se verificam nacionalmente (Brasil, 2010; Brasil, 2012).

Ademais, as informações aqui obtidas revelam uma maior necessidade de investimentos na qualificação de educadores na formação inicial e continuada possibilitando o acesso ao conhecimento e a sua produção, mais particularmente, na zona rural da região agreste/Trairí no Estado do Rio Grande do Norte.

\section{Análise da Trajetória Pessoal e Profissional das Educadoras e as Repercussões na Prática Docente}

Nesta fase de análise apresento os recortes de narrativas das educadoras rurais e urbanas que caracterizam as cinco categorias de suas trajetórias pessoais e profissionais: 1) representação pessoal; 2) vida familiar e escolar; 3) escolha da profissão, 4) formação docente, e 5) atuação docente. Dessa forma, é oportuno observar como as educadoras articulam as dimensões pessoais e profissionais através de suas experiências e saberes considerando as repercussões nas suas práticas pedagógicas. Os aportes dos autores, entre outros, Oliveira et al. (2006); Larrosa (2002); Josso (2007); Bourdieu (1964; 1966; 1970); Ferrarotti (1983; 1991) Marin $(1995 ; 2014)$ serão importantes para fundamentar as análises das narrativas sobre histórias de vida das educadoras.

A seguir apresento os recortes das narrativas sobre a representação pessoal a partir da questão: Quem Sou Eu?

Hoje acredito ser acima de tudo uma sonhadora. Sonho com o que já fiz de bom e com o que ainda posso fazer em minha vida e na vida dos meus alunos (E19)

Educação \& Realidade, Porto Alegre, v. 40, n. 3, p. 923-945, jul./set. 2015. 
Procuro sempre desempenhar minhas tarefas no trabalho ou na vida privada, com amor e dedicação, facilitando assim sua realização e eficiência. "Na vida, sempre procurei me relacionar o melhor possível com as pessoas e consegui conquistar muitas amizades que são importantes para o meu trabalho e para a minha vida pessoal" (E3).

Sou professora, gosto muito dessa profissão, tenho dez filhos e um neto, adoro minha família. Sou católica atuante na minha igreja, atualmente meio afastada, mas persevero com esperança. Sou morena, baixa, alegre [...] (E16).

Nas suas representações pessoais, os relatos das educadoras acima referenciam a dimensão profissional, o passado e o presente através da reflexão associada à prática pedagógica. Esses aspectos são considerados fundamentais para a construção do conceito de identidade docente a partir do conceito de si.

Segundo Josso (2007, p. 423) o conceito de identidade docente faz referência às múltiplas dimensões do Quem Sou Eu? E serve para situar a si mesmo e aos outros pelo viés de um sistema de referências numa coletividade e em relação a suas próprias transformações. Narrar sobre si mesmo, possibilita uma reflexão sobre a identidade docente e a reviver experiências construídas ao longo da história pessoal e profissional. Assim, por exemplo, a educadora (E19) acima, expressa no memorial o desejo para si e para os alunos sendo possível pensar em transformações do seu ser pessoal e profissional.

Para Oliveira et al. (2006, p. 553) “[...] a identidade docente está articulada às referências de gênero, familiares, religiosas, raciais, de classe que são carregadas de contradições, cujas marcas sociais e históricas aparecem nas narrativas orais ou escritas que as pessoas fazem de si”.

Na perspectiva sociológica de Bourdieu, o conceito de "identidade" vai ao encontro da noção de habitus ${ }^{7}$ na dialética entre o agente social e o campo social ${ }^{8}$ e se aproxima das referências de Oliveira (2006, p. 553) quando denuncia as contradições das instituições sociais. Para Bourdieu, citado por Dumora et al. (2008, p. 7) “[...] a identidade é o resultado da posição e da trajetória social do indivíduo sendo referenciada pelo ‘habitus' primário e secundário”. Segundo a autora, o indivíduo é confrontado e se reajusta as novas experiências desde a infância na sua trajetória familiar e escolar até a socialização profissional na vida adulta.

Com relação ao tema do memorial vida familiar e escolar, as educadoras abaixo referenciam à infância, às relações afetivas, às dificuldades e superações vivenciadas. Segundo Silva (2007) na vida familiar, os saberes são interiorizados a partir de competências, crenças e valores incutidos pela família e contribuem para a formação da criança, futura educadora. Segundo o autor, nas suas relações com os outros, constrói e reconstrói saberes como revelam as narrativas de diversas educadoras na infância:

930 Educação \& Realidade, Porto Alegre, v. 40, n. 3, p. 923-945, jul./set. 2015. 
Então, enquanto, a idade não chegava mamãe nos ensinava em casa. Ela não entendia nada de pedagogia, mas nos alfabetizou (E11).

São momentos inesquecíveis, os atos de brincar com os meus irmãos e principalmente com a minha mãe. O momento em que aprendi a ler, e quando meu irmão mais velho me solicitava que fizesse um ditado (E12). As histórias que mais me marcaram foram aquelas contadas por minha mãe na hora de dormir (E17).

Minhas lembranças da infância com relação à família são as melhores possíveis, pois sempre tivemos uma relação de carinho, companheirismo e amizade (E20).

Chegando à escola, a criança, futura educadora, resgata e transforma sistematicamente experiências interiorizadas na vida familiar para o contexto escolar. A figura feminina mãe professora e a professora mãe é importante para compreender a genealogia dos saberes das educadoras desde a tenra infância. Larrosa (2002, p. 26) reforça a importância dos saberes da experiência não como a aquisição pela criança de saberes científicos da escola, mas acontecimentos que ocorrem na sua vida escolar. "[...] o sujeito da experiência é, sobretudo, um espaço onde têm lugar os acontecimentos". Algumas narrativas das educadoras abaixo (E11, E12, E17, E3, E16) vão ao encontro do conceito de experiência do autor, porque não são meras informações vinculadas à infância familiar e escolar, mas, situações que lhes aconteceram e, das quais elas são os sujeitos da experiência. Nessa perspectiva é que se pode falar de experiências das dimensões pessoais na vida familiar e escolar e que contribuem para determinadas escolhas futuras.

Para caracterizar essas transformações do campo familiar para o escolar, Bourdieu (1966 apud Bonnewitz, 2002, p. 63) destaca o conceito de habitus primário que corresponde à bagagem que a criança herda da família e leva para a escola. As aquisições herdadas diferem de acordo com as classes sociais e da posição dos pais no campo familiar e dos professores no campo escolar. Assim, muitas vezes, o campo escolar que acolhe crianças com diferentes aquisições, é espaço de conflitos onde os agentes dominantes reproduzem suas dominações. Nem sempre os ditos dominados aceitam de forma harmoniosa essa dominação na escola:

Considerava meus professores como meus segundos pais, minha escola como a exteriorização da minha casa (E5).

Como eu já sabia ler e escrever, aprendi com mamãe antes de ingressar na escola [...] (E3).

Gostava de auxiliar a professora com a bolsa e os livros nas idas e vindas da escola porque minha mãe também era professora (E16).

Já as recordações que tinha da escola são as amizades, as brincadeiras e o modelo de ensino das professoras (E4).

Já sobre a escola lembro de brincar no parquinho de cantigas de roda. Minha relação com os professores, quando criança era uma relação de submissão, no qual regras tinham de ser seguidas e eles eram os que mandavam e sabiam de tudo (E15). 
Bourdieu $(1964 ; 1966 ; 1970 ; 1987)$ utilizou, além do habitus, outros conceitos para denunciar essas relações desiguais entre a família e a escola: entre outros, "a violência simbólica, os herdeiros e escola conservadora”. Em relação à educadora (E15) acima, suas narrativas revelam um conflito entre ela e seus professores envolvendo a cultura familiar no campo social da escola. Esses conflitos foram referenciados por Bourdieu (1966 apud Bonnewitz, 2002, p. 63) no campo social como espaço de conflitos onde os agentes dominantes visam reproduzir suas dominações. Nessa direção, subjacente ao acesso da criança à escola, Bourdieu e Passeron (1970) denunciam também a violência simbólica exercida pela instituição de ensino e que envolve a desvalorização do saber e do saber-fazer socialmente legitimados pela cultura familiar.

Bourdieu (1987, p. 200) em entrevista concedida à Verlie na French Review, demonstra surpresa com os resultados de suas pesquisas em relação ao reconhecimento da cultura dominante pelos dominados nas suas palavras traduzidas: “[...] na verdade, o que me surpreendeu em meus trabalhos empíricos foi que, em extraordinário grau, a cultura dominante é reconhecida por aqueles que não a possuem”. No presente artigo, as afirmações de Bourdieu acima são confirmadas: poucas educadoras a exemplo de (E15), não reconheceram essa dominação e lançaram críticas contra o poder institucionalizado e contra uma relação de submissão provocando conflito com os professores na época em que eram crianças. Essa época, de acordo com os arquivos de (E15) do presente artigo, data do início dos anos de 1980 e aponta para uma imposição da cultura institucional de educação proveniente da ditadura militar e que, ainda de forma fragmentada, perdura até os dias atuais. Na perspectiva sociológica de Bourdieu e Passeron (1964) a escola, legitimada pela sociedade, reproduz a cultura do poder institucional. Nesse sentido, Nogueira e Nogueira (2002, p. 5-6) destacam:

\begin{abstract}
Cobra-se que os alunos tenham um estilo elegante de falar, de escrever e até mesmo de se comportar; que sejam intelectualmente, curiosos, interessados e disciplinados; que saibam cumprir adequadamente as regras da 'boa educação'. Essas exigências só podem ser plenamente atendidas por quem foi previamente (na família) socializado nesses mesmos valores. [...] Enquanto para as outras crianças significaria algo estranho, distante, ou mesmo ameaçador.
\end{abstract}

Na sua obra Les Héretiers, Bourdieu e Passeron (1964) também revelam como a escola não é uma instituição de educação neutra a serviço de todos. Para os autores, a escola é um forte mecanismo de reprodução social que confirma e reforça as desigualdades favorecendo as classes dominantes, das quais, seus membros são herdeiros privilegiados.

Em relação ao tema do memorial a escolha da minha profissão, as educadoras narraram suas escolhas profissionais mobilizando suas experiências no contexto escolar e familiar: 
Escolhi essa profissão por influência da professora e da minha mãe que era professora (E2).

[...] Cuidava de meus irmãos mais novos, dessa maneira, tinha habilidade e acabei ingressando no magistério, e estou até hoje em sala de aula (E6). Foi minha vida escolar que descobri minha vocação. Ser professora. E ela foi bem fundamentada e trabalhada pelas instituições e professores que tive (E7).

Espelhando-se sempre nos pontos positivos e também negativos dos professores que passaram em minha vida, nasceu o desejo de ser professora (E10).

Infelizmente foi um pedido da minha mãe [...] mas, quando recebi a proposta de lecionar descobri o desejo dentro de mim (E11).

Por influência da família (E14).

Minha mãe era professora particular em casa, minhas três madrinhas também eram. Só sei que elas me inspiraram bastante para essa escolha (E16).

Quando era criança sempre brinquei de professora, e por minha mãe ser professora, acredito que influenciou bastante a escolha dessa profissão (E19).

Nas memórias das educadoras acima é possível perceber, sobretudo, a influência das experiências da vida familiar e escolar na escolha da profissão. Os saberes retirados dessas experiências brotam, assim, deste convívio relacional onde as educadoras foram fortemente influenciadas. De acordo com Josso (2007, p. 414) “[...] todo projeto de formação cruza, à sua maneira e nas palavras de seu autor, com a temática da existencialidade associada à questão subsequente da identidade para si e identidade para os outros". Nessa perspectiva, a autora (Josso, 2007, p. 431) afirma: "[...] mas não se pode perder de vista nesta identidade para si que não há individualidade sem ancoragens coletivas (família, pertenças e grupos diversos, sobre os quais todos e cada um têm uma história!)".

Segundo Marin (1995) valores, crenças e saberes da infância na família são levados para a escola e reutilizados na escolha da profissão e na formação docente. Para a autora (2014, p. 73-77), de acordo com recentes estudos realizados em São Paulo, as professoras de pedagogia reproduziram as mesmas condições que vivenciaram na infância escolar na aprendizagem da leitura e da escrita. A autora destaca a existência de uma reprodução na escola das desigualdades contemporâneas e que essa reprodução aponta para as desigualdades originárias, transformando o pouco que a escola fornece em mecanismos classificatórios: "[...] como uma das professoras disse sobre a leitura coletiva: nem todos acompanharam" "Estes serão os excluídos do interior da escola" (Marin, 2014, p. 77).

Na perspectiva sociológica, as conclusões de Marin (2014) reforçam as constatações de Bourdieu (1966) na obra L'École Conservatrice [...] sobre a importância da herança transmitida pela cultura familiar e as desigualdades de classes sociais reproduzidas pela escola. Para Bourdieu (1966, p. 326) "[...] a herança cultural que difere de acordo com a 
classe social, é responsável pela desigualdade inicial das crianças nas dificuldades escolares e assim, na desigualdade do sucesso". Dessa forma, esse aspecto remete a compreensão de que a herança cultural dos pais herdada para os filhos deve ser reconhecida, inclusive para o desempenho acadêmico no sistema escolar que reproduz a cultura das classes dominantes.

Em relação ao tema do memorial minha formação docente, as educadoras narraram sobre suas experiências do magistério e da graduação. De acordo com Tardif; Lessard; Lahaye (1991), os saberes da experiência não são ensinados nos cursos de formação, mas auxiliam na apropriação dos saberes formalizados, sejam eles disciplinares, curriculares e profissionais. Assim, as habilidades da prática com crianças antes da formação no magistério e a utilização das experiências positivas no estágio do magistério aprendidas com os professores nas narrativas abaixo, são exemplos que ilustram os saberes tirados da experiência, trazidos pelas educadoras (E6 e E10) e que interagiram com os saberes profissionais na formação.

Dessa maneira, tinha habilidade em cuidar de crianças e acabei ingressando no magistério, e estou até hoje em sala de aula (E6).

[...] Fui contemplada com uma vaga de estágio em uma escola publica, da qual fui aluna quando criança. [...] Procuro passar para os meus alunos os pontos positivos que aprendi com os meus professores no magistério (E10).

Na formação, cada disciplina foi cursada com dedicação. [...] (E1).

Decidi cursar Pedagogia para me apropriar da prática do ensino infantil [...] (E5).

[...] comecei o curso de Pedagogia. Este curso foi muito importante para a minha vida profissional, pois me deu oportunidade de estar sempre refletindo em minha prática e essa reflexão tem me proporcionado mudanças significativas (E8).

Na perspectiva experiencial de Josso (2004) as narrativas da educadora (E8) acima são legitimadas a partir do conceito de experiência formadora. Para a autora (2004) além da dimensão científica, existe também uma formação profissional, seja inicial ou continuada. Segundo ela, refletir e tirar proveito de ações na formação é fundamental para uma experiência formadora. "[...] vivemos uma infinidade de vivências; estas vivências atingem o status de experiências a partir do momento que fazemos um certo trabalho reflexivo sobre o que se passou e sobre o que foi observado, percebido e sentido" (Josso, 2004, p. 48). Segundo a autora, a experiência somente é formadora quando existir aprendizagem que simboliza atitudes, comportamentos, pensamentos, saber fazer, sentimentos e que caracterizam uma subjetividade e identidade.

Apesar das suas motivações profissionais, as narrativas, principalmente, da educadora (E8) acima, me parece “[...] acríticas e romanescas apresentando retóricas ${ }^{9}$ ”. Ao mesmo tempo em que existe uma intenção em comunicar utilizando uma linguagem da cultura profissional, há também uma tentativa de convencer ou iludir o leitor. Nesse 
sentido, a realidade profissional de (E8) viabilizada pelo curso de pedagogia, por si só, não me parece suficiente para possibilitar, segundo ela, a apropriação da prática do ensino infantil, da reflexão sobre si proporcionando mudanças significativas. Enfim, eu ainda questiono se a educadora (E8) não estaria enganada ou iludida, juntamente com os seus grupos específicos ou leitores, em acreditar na verdade única de uma pedagogia institucionalizada ${ }^{10}$ ? Uma questão me parece relevante para refletir sobre as narrativas da educadora (E8): Nessas narrativas, estariam contidas informações intencionais que poderiam vir a ser objeto de pesquisa científica ou apenas retóricas ilusórias do senso comum superadas pelos critérios do conhecimento científico?

Essa questão aponta para um confronto entre duas perspectivas sociológicas divergentes: a primeira referencia à autonomia do método autobiográfico de Ferrarotti (1991) e a segunda referencia a ilusão biográfica defendida por Bourdieu (1986). A história de vida como método científico é uma reivindicação da primeira perspectiva. Um dos aspectos relevantes do método heurístico e hermenêutico é a união entre a história individual com a história social do indivíduo. Segundo Ferrarotti (1991) essa integração nasce de uma intencionalidade comunicativa segundo a qual, o individuo não é neutro, ele sempre tem a intenção de comunicar sua história de vida a alguém do grupo primário de pertença, entre outros, a família, o grupo profissional, o grupo específico de leitores, os pares. Para Bueno (2002, p. 20) “[...] quem conta a sua vida não conta a um gravador”. Assim, a educadora (E8) nas suas reflexões, exalta a sua a trajetória de formação individual se apropriando das possibilidades disponibilizadas pelo social.

A segunda perspectiva defendida por Bourdieu (1986) lança críticas às histórias de vida como objeto de pesquisa científica e de formação refutando o aspecto heurístico e hermenêutico pretendido por Ferrarotti. "As histórias de vida são uma dessas noções do senso comum que entraram como contrabando no universo científico; no início, sem muito alarde, entre os etnólogos, depois, mais recentemente, e não sem ruídos, entre os sociólogos” (Bourdieu, 1986, p. 69). Mais adiante o autor conclui: “[...] produzir uma história de vida, tratar a vida como uma história, ou seja, como um relato coerente de uma sequencia significativa e orientada de eventos, é talvez, sacrificá-la a uma ilusão retórica” [...] (Bourdieu, 1986, p. 70). Trata-se, portanto de uma crítica bourdieusiana em primeiro lugar, apontada para os sociólogos considerando a possibilidade de que o real não é linear, nem contínuo, não havendo assim, espaço para uma teoria biográfica a partir da utilização do senso comum. Em segundo lugar, a crítica de Bourdieu (1986, p. 70) destaca a ilusão retórica ressaltando que muitas vezes, o poder de convencer através de argumentos negligencia a possibilidade de questionar as descontinuidades, as incoerências, as rupturas da vida real onde se insere o sujeito e de criticar o poder instituído o que remete a uma das possibilidades de compreender as narrativas da educadora (E8).

Educação \& Realidade, Porto Alegre, v. 40, n. 3, p. 923-945, jul./set. 2015. 935 
Sobre o tema do memorial minha prática pedagógica as educadoras fizeram referências, nas suas narrativas, às contribuições da formação para a atuação profissional, as articulações entre teoria e prática, a importância das experiências das crianças para o conteúdo em sala de aula, a mobilização de saberes da formação para a prática pedagógica e a valorização profissional. Sendo esses aspectos fundamentais para legitimar a importância da profissão a partir da atuação individual de cada educadora. De acordo com Antunes (2007) o processo de reconstrução da história pessoal de um professor inclui lembrar e refletir sobre o que marcou também durante sua formação:

[...] cada formação me deixou bastante aprendizado e conhecimento para a minha prática como professor, também desenvolvi este aprendizado em sala de aula para os alunos. (E13) [...] contribuiu para a minha profissão [...] uma vez que todo o curso tinha como estratégia a teoria e a prática vivenciada na sala de aula (E17).

Na graduação aprendi bastante sobre a importância da professora na vida das crianças e como o ensino é algo relevante na vida delas. Sempre trabalhei de forma interdisciplinar e contextualizada [...] por isso construo o conhecimento junto com eles (E19).

[...] as crianças nos acrescentam sempre suas vivencias, suas experiências diárias e são exatamente essas vivencias que direcionam em sua maioria as minhas praticas educacionais (E14).

Ensino crianças porque também acredito em Paulo Freire [...] Como professora procuro trabalhar minha disciplina da forma mais agradável possível (E5).

As narrativas das educadoras revelam ainda que as ações em sala de aula com os alunos não são provenientes apenas dos cursos de formação, mas também, dos saberes da experiência trazidos por elas e que vão se modificando nas suas ações pedagógicas com os alunos a exemplo de (E14 e E19). Larrosa (2002, p. 26) quando se refere aos saberes da experiência afirma: “[...] o que ocorre é que se trata de um saber distinto do saber científico e do saber da informação, e de uma práxis distinta daquela da técnica e do trabalho". Segundo o autor "[...] por isso também o saber da experiência não pode beneficiar-se de qualquer alforria, quer dizer, ninguém pode aprender da experiência de outro a menos que essa experiência seja de algum modo, revivida e tornada própria”. Assim, essas educadoras (E14 e E19) se apropriam das experiências de seus alunos, as quais passaram a fazer parte de seus saberes sendo mobilizados nas suas práticas pedagógicas como saberes da experiência.

Ademais, lendo suas narrativas é possível perceber um discurso sobre as várias etapas das histórias de vida em que os saberes de muitas educadoras foram reconstruídos e atualizados ao longo de suas trajetórias. De acordo com Brito (2011) essa ressignificação de saberes é perceptível na forma de pensar a relação entre passado e presente nas suas dimensões pessoal e profissional. Através das narrativas da Educadora (E5) é possível observar suas apropriações em relação às expressões linguísticas familiarizadas ao campo profissional ao qual se insere para

936 Educação \& Realidade, Porto Alegre, v. 40, n. 3, p. 923-945, jul./set. 2015. 
narrar sobre sua prática pedagógica: a credibilidade de Paulo Freire no contexto educacional a valoriza individualmente e socialmente concede confiabilidade a sua profissão. Essa articulação entre a dimensão individual e social nos remete a Ferrarotti (1991) para quem, na historia social e individual, o sujeito é ativo se apropria da dimensão social através de suas práticas subjetivas.

Retomando o debate entre as perspectivas sociológicas de Bourdieu (1988) e de Ferrarotti (1991) ainda a partir da educadora (E5), é oportuno destacar a existência de intenção e subjetividade. Assim, quem narra, comunica alguma coisa, ou seja, tem uma intencionalidade marcada por uma vida que não é objetiva. Nesse sentido, Ferrarotti (1991) ressalta que o individuo sempre se dirige, nas suas narrativas, para o seu grupo primário ao qual pertence.

A despeito de que não existe neutralidade na compreensão sociológica da escola, Bourdieu admite também que existe intenção nas narrativas do sujeito. Entretanto, ele recusa que a subjetividade do campo social e do próprio sujeito seja reificada considerando ainda o mau uso do artefato história de vida como objeto de conhecimento científico. Nas suas palavras traduzidas (Bourdieu, 1986, p. 71): "Tentar compreender uma vida como uma série única de sucessivos acontecimentos em si suficientes, com ligação apenas ao ‘sujeito' cuja constância é somente possuir um nome próprio, é tão absurda” [... ${ }^{11}$.

Entretanto, existem posições contrárias às afirmações de Bourdieu (1986). Ainda que na perspectiva de Ferrarotti (1991) a vida individual e social do sujeito não seja linear nem continua, Pineau e Le Grand (2012) apud Passeggi (2014, p. 227) ressaltam a possibilidade, segundo a qual as narrativas assumam um papel delineador na trajetória de vida desse sujeito: "É a narrativa que empresta à vida uma sequência, cria um percurso orientado, linear, da história" [...] "o surgimento de uma ruptura, de um acontecimento cujo sentido é buscado e construído depois". Os autores concluem: "E é justamente porque a vida humana não é uma história, mas intervalos de turvação às voltas com múltiplas histórias, continuidades e descontinuidades a serem articuladas, que os vivos procuram fazer da vida uma história”. Assim, Pineau e Le Grand (2012) apud Passeggi (2014, p. 227) postulam que, a partir da relação entre os aspectos psicológicos e sociais, os indivíduos podem utilizar as narrativas de história de vida para explicar as rupturas entre os acontecimentos da vida e assim, legitimá-las como instrumento de pesquisa.

Ferrarotti (1991) também rebate as críticas lançadas por Bourdieu (1986) e postula a possibilidade de tornar a subjetividade das narrativas autobiográficas em objeto de conhecimento científico. $\mathrm{O}$ primeiro autor reivindica a superação da formalidade e da linearidade do modelo mecanicista que caracterizava a epistemologia estabelecida através de um conjunto de procedimentos. A superação pretendida, segundo o autor, foi alcançada pela caracterização heurística, hermenêutica, histórica e subjetiva que legitimam o método científico. O objetivo de

Educação \& Realidade, Porto Alegre, v. 40, n. 3, p. 923-945, jul./set. 2015. 
Ferrarotti (1991) no início dos anos de 1950 era dar autonomia ao que ele denominou de método biográfico. Postulando que a história é dialética e que seu conteúdo faz parte da práxis humana entre indivíduo-mundo, o autor utilizou a razão dialética de Marx, VI tese de Feuerbach para caracterizar a relação como fonte reveladora do individuo que dá significado ao sistema sociall ${ }^{12}$.

É através das apropriações pelo individuo do processo de interiorização/exteriorização e estruturação/desestruturação com repercussões no desenvolvimento das estruturas psicológicas do indivíduo que Ferrarotti (1991) explica a dinâmica da subjetividade e da hermenêutica. $\mathrm{O}$ autor valida e legitima o método autobiográfico como mediador entre a história individual e social reconhecendo-o como objeto de pesquisa. Segundo o autor, nesse processo o indivíduo realiza interações sociais com os seus grupos imediatos que este autor denomina de grupos primários: entre outros, a família, os pares, a profissão. Nas palavras do autor:

O grupo torna-se, por seu lado -, o objeto da práxis sintética dos seus membros. Cada um 'lê' o grupo e dele faz uma interpretação particular segundo a sua própria perspectiva; cada um constrói um sentido de si na base da sua percepção do grupo de que é membro. O grupo primário revela-se assim como a mediação fundamental entre o social e o individual (Ferrarotti, 1991, p. 175).

Essas reflexões sobre a leitura e a interpretação que cada indivíduo faz do seu grupo remete de volta à discussão sobre várias educadoras deste artigo, inclusive (E5) em que leram e foram lidas pelo seu grupo principalmente familiar, escolar e profissional nas suas trajetórias de vida da infância à vida adulta. Em particular, as educadoras recorreram às expressões com as quais estão familiarizadas no grupo, em cada época de suas histórias, e que representam a sua identidade narrativa.

\section{Considerações Finais}

Discutir sobre as narrativas das educadoras numa perspectiva experiencial e sociológica foi o principal objetivo do artigo. Este objetivo possibilitou debater com essas educadoras lembranças fomentadoras de desafios e decisões raramente utilizadas por elas na formação e na prática docente ${ }^{13}$. As narrativas retrataram um passado em que elas resgataram como atoras, as suas significações sociais e concepções de si e do contexto ao longo da história de vida.

Em atendimento aos objetivos e aos aspectos metodológicos de discussão do artigo, considerei dois pontos de conclusão. O primeiro referiu-se ao perfil pessoal e profissional das educadoras da zona urbana e rural. O segundo tratou da história de vida individual e social e das articulações entre essas duas dimensões discutidas numa perspectiva experiencial e sociológica.

938 Educação \& Realidade, Porto Alegre, v. 40, n. 3, p. 923-945, jul./set. 2015. 
Em relação ao primeiro ponto, elevadas médias de idade e de experiência profissional foram identificadas na maioria das educadoras, possibilitando uma quantidade maior de informações e tornando a análise qualitativa das narrativas, mais rica em detalhes. As educadoras urbanas apresentaram resultados mais elevados em termos de nível de ensino e de participação em eventos científicos comparativamente às educadoras rurais. Assim, as políticas públicas na formação inicial e continuada nas pequenas cidades e distritos pesquisados na zona rural, ainda apresentam investimentos pouco significativos. De acordo com indicadores governamentais, as educadoras necessitam de uma melhor estrutura de formação inicial e continuada no campo e nas pequenas cidades sem, portanto, descaracterizá-las; mas, de envolvê-las cada vez mais no contexto cultural, democratizando, ao mesmo tempo, o acesso ao conhecimento.

Em relação ao segundo ponto, observei as articulações entre as dimensões pessoais e profissionais a partir de várias etapas da história de vida, seja a representação pessoal, a vida familiar e escolar, a escolha da profissão, a formação e a prática docente. Nesse ponto de analise surgiram duas modalidades: a primeira se referiu à perspectiva experiencial e a segunda à perspectiva sociológica.

Na perspectiva experiencial, as narrativas das educadoras revelaram que as ações pedagógicas com os alunos foram provenientes tanto dos saberes profissionais na formação quanto dos saberes a partir das experiências; estes últimos, trazidos por elas a partir de suas vivências da infância no convívio familiar e escolar. Outro aspecto a considerar foi a reflexão sobre as práticas pedagógicas recebidas na infância; sobretudo, apontou dificuldades e possibilidades a partir de significações atribuídas às situações vivenciadas. Essas significações quando reconstruídas ao longo da história de vida, tiveram implicações na atualização das ações formativas e pedagógicas das educadoras.

De acordo com as discussões, as narrativas de várias educadoras contemplaram o conceito de experiência formadora de Josso considerando que na narração dos processos de formação, o sujeito conhece e aprende a partir de suas próprias experiências de vida. Nesse sentido, a trajetória dos saberes da experiência revelou transformações desde a vida escolar e até a prática pedagógica onde se imbricaram com os saberes profissionais. As experiências escolares do passado de várias educadoras foram repensadas por elas ao longo de suas carreiras profissionais e resignificadas no seu trabalho docente atual. Nessa perspectiva, as narrativas autobiográficas se revelaram como uma alternativa próspera destacando a pesquisa, a atualização das estratégias de formação docente, a compreensão do desenvolvimento das dimensões individuais e sociais das educadoras e suas identidades e subjetividades.

As relações entre essas duas dimensões foram compreendidas pelas perspectivas sociológicas neste artigo como interações entre as 
educadoras e seus grupos de pertença ou campo social na segunda modalidade de análise referenciada por duas perspectivas sociológicas divergentes.

As perspectivas sociológicas de Ferrarotti e de Bourdieu contribuíram para a discussão e compreensão das histórias de vida das educadoras a partir da subjetividade nas relações entre o individual e o social e entre as classes de dominados e dominantes. Essas relações foram compreendidas neste artigo através das informações intencionais contidas nas narrativas marcadas, entre outros aspectos, por conflitos, tensões e retóricas dirigidas pelas educadoras, aos grupos de pertença, entre outros, a família, a escola, e a profissão. Assim, as retóricas contidas nas narrativas foram interpretadas com a intencionalidade de convencer ou iludir os grupos em questão considerando duas possibilidades: as educadoras utilizaram a apropriação da linguagem profissional do grupo de pertença para convencê-lo; ou elas e seus grupos de pertença foram iludidos pela verdade única de um conhecimento institucionalizado. Utilizei as concepções críticas de Bourdieu para destacar as relações de tensões, conflitos e retóricas dos sujeitos como agentes sociais de classes ditas dominadas dirigidas aos grupos do poder estabelecido, dito dominante. Essas relações foram denunciadas por Bourdieu como produto das desigualdades sociais reforçadas pela escola. Entretanto, Bourdieu não reconheceu a cientificidade das narrativas. Ele utilizou o conceito de ilusão retórica para explicar que o poder de convencer através de argumentos contidos nas narrativas é ilusório porque poderia negligenciar ou desviar o direcionamento de críticas ao poder instituído ou dominante, ou seja, ser cúmplice da escola como principal reprodutora das desigualdades sociais. A reprodução das desigualdades contemporâneas na escola brasileira foi também denunciada por Marin como mecanismo classificatório dessas desigualdades na escolarização.

Ferrarotti defendeu as informações contidas nas narrativas como fruto do processo dialético de interiorização/exteriorização e desestruturação/ estruturação psicológica entre o indivíduo e seu grupo primário. Ele reconheceu a superação do modelo mecanicista pelo método autobiográfico legitimando a sua autonomia, seu aspecto dialético, hermenêutico e histórico nas articulações entre a história individual e social como elementos que validam o conhecimento científico. Bourdieu refutou essa possibilidade apontando para a ilusão biográfica e referindo-se a reificação, ao senso comum e ao mau uso do artefato história de vida como elementos que não atenderiam aos critérios do conhecimento científico.

As análises das perspectivas de Ferrarotti e de Bourdieu sobre as subjetividades contidas nas narrativas sobre histórias de vida foram, portanto, fundamentais para o avanço das discussões nesse artigo.

Por último, os limites deste estudo são caracterizados pelo número reduzido de cidades, distritos e educadoras investigadas. Assim, seus resultados não podem ser generalizados para outras cidades ou regiões 
brasileiras considerando os aspectos estruturais, sociais e culturais. Mas, ao mesmo tempo, com base nas discussões dos autores, considero as desigualdades de acesso ao conhecimento que ainda se verificam no país. Desde que, observados os limites estabelecidos, ressalto as contribuições das narrativas sobre histórias de vida e sobre saberes dos professores como elementos de transformação pessoal e profissional com possibilidades de mudanças na realidade sociocultural onde elas se inserem.

Recebido em 23 de janeiro de 2014 Aprovado em 28 de novembro de 2014

\section{Notas}

${ }^{1}$ Passeggi (2010, p. 21) considera o memorial autobiográfico como: [...] "uma escrita institucional na qual a pessoa que escreve faz uma reflexão crítica sobre os fatos que marcaram sua formação intelectual e/ou sua trajetória profissional, com o objetivo de situar-se no momento atual de sua carreira e projetar-se em devir". A autora conclui: o memorial autobiográfico "é uma escrita de si, uma narrativa descritiva e reflexiva sobre uma trajetória de vida e de formação". De acordo com Severino (2001, p. 175) trata-se de [...] "uma narrativa simultaneamente histórica e reflexiva" (Passeggi, 2010, p. 21). Assim, o presente artigo utilizou um memorial como um documento do método autobiográfico para coleta de narrativas sobre histórias de vida.

${ }^{2}$ Para Brito (2011, p. 5) ao longo da história de vida dos professores as dimensões pessoais estruturam o conhecimento de si e as relações com os outros construindo saberes da experiência que interagem, posteriormente, com os saberes profissionais na prática pedagógica.

${ }^{3}$ As considerações de Bertaux (1981, apud Bueno, 2002, p. 16) e de Ricoeur e Eric (1984) ilustram bem essa polêmica sobre a definição de termos. Inicialmente o primeiro autor “[...] distingue estórias de vida - relatos sobre a vida de alguém, narrados oralmente pela própria pessoa - de histórias de vida-trabalho com diversos tipos de documentos com vistas a estudar a vida de uma pessoa, ou grupo, e que, portanto, inclui a primeira abordagem”. Em seguida, Ricoeur e Eric (1984) distinguem a narrativa como relato e a narrativa como abordagem investigativa. Segundo os autores três eixos distinguem o primeiro caso: história de vida, biografia e autobiografia. O segundo caso, refere-se a uma prática da pesquisa qualitativa.

${ }^{4}$ Inclui-se na zona urbana a cidade litorânea do Natal, capital com 818.000 habitantes e na zona rural no interior do estado, as cidades de Japi com 5.500 habitantes, de Campo Redondo com 10.300 habitantes, de Tangará com 11.200 habitantes, de Santa Cruz como cidade polo com 36.500 habitantes e distritos rurais circunvizinhos com menos de 2.000 habitantes.

${ }^{5}$ Os saberes da experiência, como elemento de reflexão do professor/pesquisador de seu próprio trabalho docente, em particular, possibilita validar novas alternativas susceptíveis de repercutir na sua realidade social. As pesquisas realizadas no Brasil por Therrien (1996) destacam que as professoras do campo recorrem à experiência da prática, do fazer, da ação pedagógica ou da experiência de investigação elementar, conforme o caso, a qual tem sua racionalidade e seus saberes validados nos contextos onde se situam. Essas pesquisas con- 
stataram que as professoras do campo sem formação profissional recorriam aos saberes da experiência construídos anteriormente e atualizados com as experiências da prática pedagógica.

${ }^{6} \mathrm{O}$ número elevado de 40 educadoras considera dois aspectos: o primeiro referese ao objetivo "1" deste estudo e visa discutir dados estatísticos sobre níveis do perfil pessoal e profissional entre educadoras da zona urbana e rural: gênero, idade, formação, participação em eventos científicos e tempo de experiência profissional; o segundo aspecto visa articular os dados estatísticos do perfil com os dados qualitativos dos memoriais autobiográficos no sentido de contribuir para as reflexões teóricas sobre história de vida das educadoras.

${ }^{7}$ Para Bourdieu, 1966 apud Bonnewitz (2002, p. 63) as novas aquisições que o sujeito incorpora ao longo de sua experiência na trajetória escolar até a vida adulta é denominada de "habitus secundário" sendo de grande importância, uma vez que suporta o "habitus" familiar (primário). "Essa integração entre habitus "primário e secundário" transforma o conjunto existente em um único "habitus" evolutivo e que se reajusta e se reestrutura em função de novas e inesperadas situações que ocorrem na trajetória social do sujeito” (Bonnewitz, 2002, p. 63).

${ }^{8}$ Um “campo social" é um espaço estruturado e hierárquico de cargos ou posições cujas características são relativamente independentes de seus ocupantes. [...] Um campo social aparece como um espaço de conflitos onde os agentes dominantes visam reproduzir suas dominações (Bourdieu apud Bonnewitz, 2002, p. 34).

${ }^{9}$ A retórica é considerada como a arte de convencer alguém pelo discurso escrito ou oral. Segundo Reale (2010), para alcançar a verdade, pela qual a retórica teria de se submeter, se faz necessária a aprendizagem da doutrina das ideias e a dialética "[...] seja no seu momento ascendente que leva do múltiplo ao uno, seja no seu momento descendente que ensina a dividir as ideias segundo as articulações que lhe são próprias".

${ }^{10}$ Essa questão nos remete às críticas denominadas de "dialética sem diálogo" por Pimenta e Mazzoti no seu artigo: Análise Retórica da Filosofia da Educação Brasileira (2004) direcionadas à tese de doutorado de Dermeval Saviani: Educação Brasileira: estrutura e sistema, publicada na sua 8. ${ }^{a}$ edição em 2000. Segundo os autores (2004, p. 2): "[...] nem ele e nem seus auditórios percebem os enganos em que estão envolvidos, pois pretendem, antes de tudo, realizar uma transformação social [...] ao sustentar que o senso comum de uma época foi consciência filosófica de outra".

${ }^{11}$ As citações originais no texto em língua francesa foram traduzidas pelo autor deste artigo.

${ }^{12}$ Ferrarotti (1991) sugere que o pesquisador utilize o método biográfico através de materiais primários, frequentemente uma entrevista face a face para mediar as significações entre a historia individual e social do individuo.

${ }^{13}$ Esse debate foi possível em um encontro sobre história de vida e prática docente que realizei com as educadoras após a conclusão desta pesquisa.

\section{Referências}

ANTUNES, Helenise Sangoi. Relatos Autobiográficos: uma possibilidade para refletir sobre as lembranças escolares das alfabetizadoras. Educação, Santa Maria, UFSM, v. 32, n. 1, p. 81-96, jan./jun. 2007. 
BONNEWITZ, Patrice. Pierre Bourdieu: vie, oeuvre, concepts. Paris: Ellipses, 2002.

BORGES, Priscilla. Um Terço dos Professores do Campo tem Formação Inadequada. Disponível em: <http://www.todospelaeducacao.org.br/educacao-no-brasil>. Acesso em: 12 abr. 2012.

BOURDIEU, Pierre. Esquisse d'un Projet Intellectuel: un entretien avec Pierre Bourdieu par Claud Du Verlie. The French Review, v. 62, n. 1, p. 194-205, dec. 1987.

BOURDIEU, Pierre. L'Illusion Biographique. Actes de la Recherche en Sciences Sociales, v. 62-63, n. 1, p. 69-724, juin. 1986.

BOURDIEU, Pierre. L'École Conservatrice. Les Inégalités Devant L'école et Devant la Culture. Revue Française de Sociologie, Paris, v. 7, n. 3, p. 325-347, juil./ sept. 1966.

BOURDIEU, Pierre. Questions de Sociologie. Paris: Les Éditions de Minuit, 1988. BOURDIEU, Pierre. Science de la Science et Réflexivité. Paris: Raisons D’agir, 2001.

BOURDIEU, Pierre; PASSERON, Jean-Claude. La Reproduction: éléments d'une théorie du système d'enseignement. Paris: Les Éditions de Minuit, 1970. coll. Le sens commun.

BOURDIEU, Pierre; PASSERON, Jean-Claude. Les Héritiers. Les Étudiants et la Culture. Paris: Les Éditions de Minuit, 1964. coll. Le sens commun.

BRASIL. Lei no 9.394, de 20 de dezembro de 1996. Ministério da Educação e Cultura. Estabelece as Diretrizes e Bases da Educação Nacional. Diário Oficial da União, Brasília, DF, v. 134, n. 248, 23 dez. 1996, seção I, p. 27834-27841.

BRASIL. Ministério da Educação. Instituto Nacional de Estudos e Pesquisas Educacionais. Microdados da Educação Básica/Censo Escolar 2010. Brasília, 2010.

BRASIL. Ministério da Educação. Pronacampo: programa implementará educação do campo e atenderá 76 mil escolas. Brasília, DF, 2012. Disponível em: $<$ http://portal.mec.gov.br /index.php?option=com>. Acesso em: 15 dez. 2013.

BRITO, Daniel Bezerra. Prática Pedagógica, Saberes e Histórias de Vida: reflexões sobre manuscritos autobiográficos. In: SEMINÁRIO NACIONAL DO ENSINO MÉDIO, 1, 2011, Mossoró. Anais... Mossoró: nov. 2011. P. 71-83.

BUENO, Belmira. O Método Autobiográfico e os Estudos com Histórias de Vida de Professores: a questão da subjetividade. Educação e Pesquisa, São Paulo, v. 28, n. 1, p. 11-30, jan./jun. 2002.

DUMORA, Bernadette et al. Les Perspectives Contextuelles de L'Identité. L'Orientation Professionnelle, France, v. 37, n. 3, p. 387-411, avr. 2008.

FERRAROTTI, Franco. Histoire et Histoires de Vie: la méthode biographique en sciences sociales. Trad. Marianne Modak. Paris: Méridiens Klincksieck, 1983.

FERRAROTTI, Franco. Sobre a Autonomia do Método Biográfico. Sociologia: problemas e práticas, Lisboa, Editora Novos Mundos, n. 9, p. 171-177, mar. 1991. FREITAS, Maria Teresa de Assunção. A Abordagem Sócio-histórica como Orientadora da Pesquisa Qualitativa. Cadernos de Pesquisa, São Paulo, Fundação Carlos Chagas, n. 116, p. 21-39, jul. 2002.

JOSSO, Marie Christine. Experiência de Vida e Educação. Educação, Porto Alegre, n. 3, p. 413-438, set./dez. 2007. 
JOSSO, Marie Christine. Experiências de Vida e Formação. São Paulo: Cortez, 2004.

LARROSA, Jorge. Notas Sobre a Experiência e o Saber de Experiência. Tradução de João Wanderley Geraldi. Revista Brasileira de Educação, Rio de Janeiro, ANPED, n. 19, p. 20-28, jan./abr. 2002.

MARIN, Alda Junqueira. A Produção da Desigualdade na Escolarização: aspectos da vida contemporânea e o trabalho pedagógico. Educação, Porto Alegre, v. 37, n. 1, p. 72-78, jan./abr. 2014.

MARIN, Alda Junqueira. Educação Continuada: introdução a uma análise de termos e concepções. Cadernos Cedes, Campinas, UNICAMP, v. 36, p. 13-20, nov./dez. 1995.

MOITA, Luiz Paulo. Pesquisa Interpretativista em Linguística Aplicada: a linguagem como condição e solução. D.E.L.T.A., São Paulo, v. 10, n. 2, p. 329-328, jan. 1994.

NOGUEIRA Cláudio; NOGUEIRA, Maria Alice. A Sociologia da Educação de Pierre Bourdieu: limites e contribuições. Educação e Sociedade, Campinas, v. 23, n. 78, p. 15-36, abr. 2002.

NÓVOA, Antonio. Os Professores e as Histórias da sua Vida. In: NÓVOA, Antonio (Org.). Vidas de Professores. Porto Alegre: Porto Editora, 1995. P. 31-61.

OLIVEIRA, Zilma et al. Construção da Identidade Docente: relatos de educadores de educação infantil. Cadernos de Pesquisa, São Paulo, Fundação Carlos Chagas, v. 36, n. 129, p. 547-571, set./dez. 2006.

PASSEGGI, Maria da Conceição. Memoriais Autobiográficos: escritas de si como arte de (re) conhecimento. In: VERBENA, Maria Rocha Cordeiro; SOUZA, Elizeu Clementino de (Org.). Memoriais, Literatura e Práticas Culturais de Leitura. Salvador: EDUFBA, 2010. P. 19-42.

PASSEGGI, Maria da Conceição. Pierre Bourdieu: da "ilusão" a "conversão" autobiográfica. Revista da FAEEBA - Educação e Contemporaneidade, Salvador, v. 23, n. 41, p. 223-235, jan./jun. 2014.

PIMENTA, Rita; MAZZOTI, Tarso. Análise Retórica da Filosofia da Educação Brasileira de Saviani. Revista de Retórica y Teoría de la Comunicación, Año IV, n. 7, p. 105-116, dez. 2004. ISSN 1577-5089.

PINEAU, Gaston; LE GRAND, Jean-Louis. As Histórias de Vida. In: PASSEGGI, Maria da Conceição. Pierre Bourdieu: da "ilusão" a "conversão" autobiográfica. Revista da FAEEBA - Educação e Contemporaneidade, Salvador, v. 23, n. 41, p. 223-235, jan./jun. 2014.

REALE, Giovanni. História da Filosofia Grega e Romana III: Platão. In: LUZ, Ana Rosa. Ensaios Filosóficos, v. 1, n. 1, p. 39-53, out. 2010.

RICOEUR, Paul; ERIC, Vigne. Temps et Récit. Revue d'Histoir, Vingtième Siècle, n. 3, p. 166-167, juillet 1984 .

SAVIANI, Demerval. Educação Brasileira: estrutura e sistema. 8. ed. Campinas: Autores Associados, 2000.

SEVERINO, Antonio José. Metodologia do Trabalho Científico. 21. ed. São Paulo: Cortez, 2001.

SILVA, Maria de Lourdes. Aspectos Sócio-afetivos que Interferem na Construção da Identidade do Professor: cognição, afetividade e aprendizagem. Taubaté: Cabral, 2007.

944 Educação \& Realidade, Porto Alegre, v. 40, n. 3, p. 923-945, jul./set. 2015. 
SOUZA, Clementino. Histórias de Vida e Formação de Professores. Salto para o Futuro. Rio de Janeiro, SEED-MEC, boletim n. 1, mar. 2007.

SPARKES, Andrew; SMITH, Brett. Men, Sport, Spinal Cord Injury and Narrative Time. In: DIEHL, Vera et al. Pesquisar Exige Interrogar-se: a narrativa como estratégia de pesquisa e de formação do (a) pesquisador (a). Movimento, Porto Alegre, v. 12, n. 2, p. 09-33, maio/ago. 2006.

TARDIF, Maurice. Saberes Profissionais dos Professores e Conhecimentos Universitários. Rio de Janeiro: PUC, 1999.

TARDIF, Maurice; LESSARD, Claude; LAHAYE, Louise. Os Professores Face ao Saber: esboço de uma problemática do saber docente. Teoria \& Educação, Porto Alegre, Pannônica, n. 4, 1991.

THERRIEN, Jacques. Expérience Professionnelle et Savoir Enseignant: la formation des enseignants mise en question. In: COLLOQUE LA RÉFORME DE LA FORMATION DES MAÎTRES ET LA PROFESSIONNALISATION DE L'ENSEIGNEMENT: ENJEUX, BILANS ET COMPARAISONS INTERNATIONALES, 3, 1996, Paris. Actes... Paris, avril 1996. P. 1-19.

Daniel Bezerra de Brito é mestre em Ciências da Atividade Física e doutor Phd. em Educação na área de Psicopedagogia pela Universidade Laval, Quebec, Canadá. É professor Dr. da Universidade do Estado do Rio Grande do Norte. Publica artigo sobre temas da Educação e Formação docente. É orientador de bolsistas do PIBIC-CNPq.

E-mail: danielbezerradebrito@hotmail.com 